\title{
Public-Private Partnerships in Healthcare FINANCING: LESSONS FROM THE NEW YORK State Partnership for Long-Term Care
}

\section{By Lauren Hersch Nicholas Associate Editor: Christine Tramontano}

Abstract: This paper examines the current market for the New York State Partnership for Long-Term Care (NYSPLTC), a publicprivate partnership designed to encourage private insurance purchase. The potential market for long-term care insurance (LTCI) is analyzed based on market participants' ability to afford Partnership policies. Data from the U.S. Census and the NYSPLTC creates a demographic profile of potential purchasers. This profile identifies the subsets of the population who currently benefit from the policy and those who are eligible but not participating. The Partnership is not necessarily the best use of government resources because it may increase inequitable distribution of societal resources and may not create significant benefits to offset its costs. The policy subsidizes the cost of care for some who could fully pay, rather than dedicating limited resources to providing care for the poor. This trade-off is made under the assumption that strengthening the private LTCI market will eventually reduce reliance on publicly funded care. Long-term care financing is a market failure, as individuals do not presently have the proper incentives to make provision for the cost of possible end-of-life health and social care needs. This market failure must be dealt with in light of predicted increases in cost and increased usage of long-term care by the oldest old, our nation's fastest-growing demographic.

\section{INTRODUCTION}

Long-term care services are a necessary part of life for many older adults whose physical and or mental states preclude independent living (Bectel and Tucker, 1998). Financing long-term care is becoming an increasingly important issue in the United States as demographic changes and improved medical technology manifest themselves in an aging population. The cohort of Americans aged eighty-five and older, commonly referred to as the oldest old, are the fastest-growing segment of the American population. This age segment has the highest risk of needing long-term care (Quadango, 2002, Bectel and Tucker, 1998).

Future long-term care expenditures pose a national policy problem because the cost of long-term care late in life is in excess of most people's assets and income (Feder et al., 2000). Presently, our nation lacks a unified system for financing and delivering long-term care. Medicaid, Medicare, private insurance and out-of-pocket spending combine to fund long-term care for the elderly in a variety of settings (Quadango, 2002, Bectel and Tucker, 1998). Private insurance and Medicare only cover a small portion of the nation's long-term care costs (Weiner and Stevenson, 1998).

The present financing situation in the United States places a heavy burden on the public sector through means-based programs. Alternative approaches including increased use of private insurance may reduce public spending on more affluent adults. However, the low purchase rate in the private market and market failures associated with insurance provision create a potential role for government intervention. This paper focuses on the New York State Partnership for Long-Term Care (NYSPLTC), an intervention that has been offered in New York for several years. This program is a publicprivate partnership designed to increase reliance on the private insurance market to finance long-term care. The NYSPLTC provides Medicaid funding for policyholders who finance their care through approved private insurance policies for a minimum time period which varies based on use of home or institutional care without requiring policyholders to spend down remaining income and assets to Medicaid-qualifying levels. Partnership policies protect assets including personal savings and property that would otherwise go toward the cost of patients' care. The Partnership raises several questions for policymakers concerning the sustainability, equity, and incentive structure of existing approaches to LTC finance.

Lauren Hersch Nicholas is a first-year Master of Public Policy student concentrating in the economics of aging. She is a research assistant in The George Washington University's Center for Health Services Research and Policy. Ms. Nicholas holds a Bachelor of Science in Policy Analysis and Management from Cornell University. She completed the research for this paper in collaboration with The New York State Partnership for LongTerm Care NYSPLTC office and Professor Sharon Tennyson as part of her honors thesis at Cornell. 


\section{PUBLIC-PRIVATE PARTNERSHIPS IN HEALTHCARE FINANCING}

Demographic predictions of the aging population suggest that long-term care usage and costs will increase significantly over the next 30 years as the oldest-old cohort increases and demands more care. By 2030, it will cost approximately $\$ 100,000$ for a single patient to receive a year's worth of nursing home care. Long-term care is the largest unfunded liability in the United States. Most citizens are unprepared to finance their long-term care needs (Kahn). This is reflected in increased public expenditures for long-term care. In fiscal year 2000, Medicaid spending on long-term care reached $\$ 67.7$ billion, an 8.6 percent increase over the previous year (Burwell, 2001).

The federal government shoulders the majority of the long-term care financing burden by covering care for lowincome elderly. Medicaid provides medical care for lowincome beneficiaries and serves as a last resort for those who must spend down existing assets before qualifying for the means-tested benefit (Davidson and Marmor, 1980). Older people disproportionately qualify for Medicaid due to low-income levels. In 1996, 22 percent of the elderly population received Medicaid benefits, although the elderly population accounted for only 13 percent of the overall population (Raetzman and Joseph, 1999). Various sources attribute between 45 percent and 65 percent of Medicaid expenditures to nursing and longterm care for the elderly (Raetzman and Joseph, 1999, Robert Wood Johnson Foundation, 2001). Medicaid expenditures are typically the single largest expense in state budgets, leaving states with incentives to look for ways to minimize the cost of long-term care as a way to control Medicaid spending (Caldwell, 1994).

Private long-term care insurance is affordable for many people who could not afford to finance their longterm care needs out of pocket. Thus far, though, few people have decided to purchase ITCI policies. This paper considers the potential market demand for the NYSPLTC through projections using data from the Current Population Survey (CPS) and the Partnership Office. These results provide information for an evaluation of the impact of the Partnership on LTC financing for the state.

\section{PUBLIC-PRIVATE PARTNERSHIPS IN THE UNITED STATES}

The United States has not taken a strong position toward mandating long-term care coverage as many other countries have. However, several states, including New York, have introduced partnership programs that encourage residents to purchase long-term care insurance policies in return for a guarantee that the state will allow the policyholder to receive Medicaid benefits, while at the same time retain control over any remaining assets once a set amount has been allocated to care ${ }^{1}$ Partnership policies presently account for 20 percent of the long-term care insurance policies held in New York State (Takada and Breen, 2002).

New York adopted a different approach in structuring its partnership program than that used in Connecticut, California and Indiana, the other Partnership states. Instead of a dollar-for-dollar model, New York used a total assets protection model. The New York State Partnership for Long-Term Care Insurance allows partnership policyholders to receive Medicaid benefits after their private insurance policy has covered three years of nursing home care or six years of home care, while the policyholder retains all remaining assets (NYSPLTC, 2001). Medicaid benefits can only be used in-state, and current income must go toward the cost of care. However, married Partnership policyholders with community spouses ${ }^{2}$ are able to preserve significant amounts of monthly income while receiving Medicaid care. As of 2002, the community spouse is able to retain up to $\$ 2,322$ per month. After this point, 25 percent of income above the cutoff must be contributed toward the patient spouse's care. The patient himself is only allowed to keep $\$ 50$ per month for personal expenses under Medicaid guidelines (NYSPLTC, 2002).

Policymakers believe that the partnership will encourage those who would not otherwise purchase insurance to share responsibility for the cost of their future care. Partnership purchasers will effectively be substituting private insurance dollars for Medicaid expenditures. The state could realize significant savings under the partnership given that its population faces an average nursing home stay of two and one half years, while the average spend-down period is only nine to ten months (RWJF, 2001). Reducing Medicaid spending on long-term care is particularly important in New York, which faced one of the highest per capita costs in the nation for care in 1999 and 2000 (Burwell, 2001).

However, for the partnership to be effective in reducing Medicaid expenditures, it has to sell policies to those people who would not otherwise purchase LTCI and could not afford to finance their care out of pocket. The state stands to lose money if partnership purchasers are more affluent individuals who are using the policy as another form of estate planning. When New York first introduced its partnership policies, they represented the latest trends in the long-term care insurance market. All partnership policies sold by the thirteen participating insurers are required to have the following characteristics:

- Coverage for at least three years of nursing home care, six years of home care or a combination of the two (where two home care days equal one nursing home day). 
- \$155/day coverage for nursing home care; $\$ 77 /$ day coverage for home care.

- Inflation protection equal to 5 percent compounded annually,

- Care management: information, referrals, consultation on service needs and benefits.

- Fourteen days of respite care, renewable annually, to give the athome caregiver some needed rest.

- Thirty extra grace days to pay the premium, in the event that the policyholder has designated someone to be notified if the premium is not received on time.

- Special consideration for adjustment of premiums/benefits in the event of a national long-term care program.

- Review of denied requests for benefit authorization on a caseby-case basis (NYSPLTC, 2002).

These features, particularly the inflation rider and the emphasis on nursing-home care make the policies more expensive than some less comprehensive private policies. The average Partnership policy was $\$ 2,284$ in 2002 (NYSPLTC, 2002). Non-Partnership policies offer premiums ranging in price from a few hundred to thousands of dollars depending on the type of policy purchased and the policyholder's age. For example, a 55 year-old purchaser in 2001 could purchase a basic policy for $\$ 470.80$ or a more comprehensive policy for $\$ 4,260{ }^{3}$ Current private policies encourage greater provision of home care, which is less expensive for insurers to provide and perceived as a way for patients to retain dignity and autonomy (Feder et al,, 2000). While programs in the other partnership states were initially less popular than those in New York, they have evolved in response to changes in the long-term care insurance market. Policies are becoming more flexible and emphasize home-based, rather than institutional care. Connecticut and Indiana now enjoy particularly successful programs with insurers reporting high success rates selling the policies. In Indiana, partnership policies account for more than 50 percent of state ITCI policy sales, but in New York, partnership sales are below 20 percent (Takada and Breen, 2002).

State partnership programs combine with favorable tax treatment of LTCI purchases to mitigate the cost problems in the long-term care insurance market. Thus far, few studies have looked at the partnership purchasers and there is limited information about how they compare to other purchasers of LTCI. Knowing more about these two groups is important in order to analyze the impact of the partnership programs. One study interviewed partnership purchasers and compared them to the general population: McCall et al $(1997,1998)$ found that purchasers were generally motivated by education and knowledge about long-term care and were familiar with the risk of needing and financing care. Higher income was positively correlated with purchase, but only up to $\$ 100,000$, suggesting that policies are most attractive to well-off citizens, but do not appeal to the wealthiest demographic. These findings support claims that partnership programs are valuable because they encourage those who might not otherwise purchase insurance to make provisions for future costs of care.

An important result from McCall's study was a statistically significant increase in reported use of Medicaid Estate Planning (MEP) by Partnership purchasers. MEP refers to "legal and financial approaches to satisfying financial eligibility requirements for Medicaid coverage for nursing home care." (Curry et al., 2001). Fifteen percent of purchasers report engaging in various forms of MEP asset transfers, though only 9 percent of non-purchasers behaved similarly. While use of MEP is disturbing because it suggests that the government is unnecessarily subsidizing the care of those who can afford it at the expense of taxpayers and low income individuals who must rely on Medicaid, there is also evidence that the Partnership programs help to deter this behavior. Nearly 25 percent of New York purchasers surveyed reported that they would have used MEP to finance their long-term care in the absence of the Partnership (NYS data). This group is even more pronounced in Connecticut, where 32 percent of respondents used the partnership as an alternative to transferring assets to family members in order to shield them from Medicaid spend-down. (CT OPM, 2001). The Partnership seems to be particularly attractive to individuals concerned with estate planning, creating a role for policymakers to ensure that it is used as a substitute for MEP, not a complement to other techniques.

\section{RESEARCH ON THE NYSPLTC: PROFILING THE CURRENT PARTNERSHIP MARKET}

The New York State Partnership for Long-Term Care Insurance released data detailing the number of active policyholders by county through June 30,2001 , and the average cost of a day of nursing home care in 1999 by county. This data were analyzed in combination with US Census Summary File 1 data on the New York State population by county including age, sex, and racial breakdowns. Both data sources provide information about all sixty-two counties in New York State. In 2000, the population of New York State was 18,976,457. The population was 67.9 percent Caucasian and 35.2 percent of residents are 45 years or older, with 12.9 percent of the population over 65 . Adult females outnumber males; among those over 18 there are 89.3 males to every 100 females (US Census, 2001). Potential LTCI buyers would be at least 45 years old. This demographic is the focus of the paper, particularly more affluent adults who have assets to protect.

Analysis of Census and Partnership data provides a deeper understanding of the Partnership's geographic 


\section{PUBLIC-PRIVATE PARTNERSHIPS IN HEALTHCARE FINANCING}

incidence statewide. Not surprisingly, the number of policies sold in a county was found to positively correlate with the population over 45 . The Partnership should be able to sell more policies in those counties that offer a larger market size. There was also a positive relationship between sales and the average cost of a day of care, although it was not as strong. An interesting result revealed that there was a negative relationship between the average cost of a day of care and the sales density. This finding does not support the hypothesis that individuals facing higher costs of care would be more likely to purchase insurance in anticipation of future expenditures. However, this result may reflect a lack of knowledge of those in more expensive counties, or a perception that care will be unaffordable anyway which could lead to increased reliance on Medicaid Estate Planning. Alternatively, this may reflect a rural-urban split where residents of more populous areas have friends and family nearby and tend to rely on informal care.

A significant negative relationship also existed between housing density and sales density. This finding suggests that the Partnership may disproportionately affect those living in non-urban settings. This finding underscores the importance of informal care networks. Sociologists find that those living in non-urban settings tend to live further from family and friends who could provide care if needed and are more reliant on formal care systems (Quadango, 2002). The government may be more interested in encouraging those with fewer social ties to purchase insurance to ensure that those with fewer options will have access to care when they need it. There was not a significant relationship between the number of sales and housing density, but the sales density figures are a more telling indicator of the Partnership's effect in each county as it accounts for population size. The density values permit standardized comparisons of the geographically defined counties, which show wide variation in population size and landmasses. This calculation facilitates comparison between diverse areas.

Identifying the characteristics of counties with relatively high sales densities is an important way to assess the impact of the Partnership on New Yorkers. Sales density is positively correlated to the percentage of the population with Caucasian self-identified ethnicity. There was a strong negative correlation between the percentage of Caucasian residents and the cost of an average day of nursing home care. While one might expect Caucasians to enjoy a higher degree of affluence and therefore live in areas with higher costs of care, they are also more likely to live in non-urban areas where they will face lower costs of care. In this case, policymakers should be especially interested in a Partnership product that attracts non-white consumers who disproportionately live in urban areas and face higher costs of care. However, many of the urban counties with large minority populations have very low sales densities.

\section{THE POTENTIAL MARKET FOR THE NEW YORK STATE PARTNERSHIP FOR LONG-TERM CARE}

Data from the March 2001 Current Population Survey was used in conjunction with information from the New York State Partnership for Long-Term Care Insurance in order to estimate the potential market size in the state. This analysis provides greater detail about potential Partnership purchasers and those who are excluded from policy benefits because the Partnership is not affordable to them. The CPS is a highly respected, long-running sample designed to provide information about the civilian population aged 16 and above. The survey is administered by the US Census Bureau and the US Bureau of Labor Statistics. Each state's sample reflects state-specific demographic and labor-market conditions (CPS Design and Methodology, 2000). Reponses from a subset of CPS participants who live in New York State and are between the ages of forty-five and ninety (the age range of the majority of long-term care insurance policyholders) were analyzed in order to estimate the size of the long-term care insurance market. The size of the sample used was large enough to represent the state's diverse population and to allow generalizations to be made from the data.

The New York State Partnership for Long Term Care provided average premium prices for people in each age segment as of March 2001. These values were used in conjunction with the total household income values from the March CPS and a variety of ability to pay thresholds estimating the percentage of household income that can be spent on LTCI. This analysis includes the 5 percent

Table 1: Percentage of NY State Population with Assumed Ability to Afford at Least One Partnership Policy per Household

\begin{tabular}{|l|l|l|l|}
\hline & $\begin{array}{l}\text { Willingness } \\
\text { to Pay .025 }\end{array}$ & $\begin{array}{l}\text { Willingness } \\
\text { to Pay .05 }\end{array}$ & $\begin{array}{l}\text { Willingness } \\
\text { to Pay .10 }\end{array}$ \\
\hline $\begin{array}{l}\text { Unable to } \\
\text { Afford }\end{array}$ & $63.0 \%$ & $43.3 \%$ & $28.1 \%$ \\
\hline $\begin{array}{l}\text { Able to } \\
\text { Afford }\end{array}$ & $37.0 \%$ & $56.7 \%$ & $71.9 \%$ \\
\hline
\end{tabular}

Sources: March, 2001 CPS, $n=2,929$

maximum suggested by Mellor (2000) and the 10 percent maximum that Cohen et al. (1993) encourage as well as a 2.5 percent minimum value. Table 1 shows the percentage of the New York state population with the 
ability to afford at least one partnership policy per household under each assumed percentage of income a purchaser would be able to pay. The 0 -row indicates the percentage of the sample that is unable to afford the premiums as a given percentage of income, while a value of 1 shows the percentage of the sample that is able to afford coverage.

These results are important because they illustrate the uncertainty surrounding market size estimates. Depending on which ability to pay threshold is used, anywhere from 37 percent to 71 percent of the population aged $45-90$ can be considered part of the potential partnership market. Examining the income thresholds challenges some of the assumptions supporting a high willingness to pay value. It seems unlikely that an individual or a couple living on $\$ 22,000$ a year, 200 percent of the Federal Poverty Level for a two-person household, a modest income for a typical elderly couple, would be able to spend more than $\$ 2000$ on an insurance policy. Since income and assets tend to be positively correlated, people in the lower income categories are unlikely to have a lot of assets to protect, which makes the Partnership less attractive to them.

The analysis presented in Table 1 looks at the entire sample without segregating by age. The data suggest that a relatively large percentage of the population can afford insurance by including younger people who face cheaper premiums and have a small chance of needing care. The average prices by age cohort detailed in Table 2 illustrate the relative affordability of policies for younger people who have workforce income versus older people with more imminent care needs and fewer income streams. The minimum annual income required to afford the policies at the 2.5 percent, 5 percent and 10 percent thresholds are included. Note that policies start to dramatically increase in price around age 65 . The mean and median age at purchase is 63 years.

The variation in income necessary to afford premiums at different ages and assumed abilities to pay shown in Table 2 highlight the difficulty many older adults face in affording LTCI. Even at the 10 percent level, purchasers 65 and older (nearly half of current Partnership policyholders) require relatively high incomes, especially considering that this group is least likely to have labor-force income to contribute toward policy costs. However, older people who would have enough assets to benefit from the Partnership are likely to own their homes ( 89 percent do) and are unlikely to have dependent children. With fewer living expenses, they can devote more resources toward LTCI than younger people.

In addition to using values suggested by the affordability and market size literature, revealed preferences were used in order to determine what percentage of their income Partnership purchasers were generally willing to pay for their policies. In 1995, 2,267 purchasers of the New York State Partnership for Long-Term Care provided information about their annual income level in response to a mail survey. Respondents indicated their annual income according to the following categories:

$$
\begin{aligned}
& <\$ 25,000 \\
& \$ 25,000-\$ 49,999 \\
& \$ 50,000-\$ 74,999 \\
& \$ 75,000-\$ 99,999 \\
& \$ 100,000-\$ 149,999 \\
& >\$ 150,000
\end{aligned}
$$

The 5 percent of income willingness to pay estimate, as depicted in Table 1, should be seen as an upper bound

Table 2: Variation in Income Needed to Afford Premium by Age and Assumed Abilities to Pay

\begin{tabular}{|l|l|l|l|l|}
\hline Age Range & Mean NYSPTLC Pre mium & $\mathbf{2 . 5} \%$ Income & 5 \% Income & $\mathbf{1 0 \%}$ Income \\
\hline $40-44$ & $\$ 849$ & $\$ 33,960$ & $\$ 16,980$ & $\$ 8,490$ \\
\hline $45-49$ & $\$ 1,125$ & $\$ 45,000$ & $\$ 22,500$ & $\$ 11,250$ \\
\hline $50-54$ & $\$ 1,173$ & $\$ 46,920$ & $\$ 23,460$ & $\$ 11,730$ \\
\hline $55-59$ & $\$ 1,329$ & $\$ 53,160$ & $\$ 23,580$ & $\$ 13,290$ \\
\hline $60-64$ & $\$ 1,780$ & $\$ 71,200$ & $\$ 35,600$ & $\$ 17,800$ \\
\hline $65-69$ & $\$ 2,360$ & $\$ 94,400$ & $\$ 47,200$ & $\$ 23,600$ \\
\hline $70-74$ & $\$ 3,481$ & $\$ 139,240$ & $\$ 69,620$ & $\$ 34,810$ \\
\hline $75-79$ & $\$ 5,634$ & $\$ 225,360$ & $\$ 112,680$ & $\$ 56,340$ \\
\hline $80+$ & $\$ 5,992$ & $\$ 239,680$ & $\$ 119,840$ & $\$ 59,920$ \\
\hline All & $\$ 2,284$ & $\$ 91,360$ & $\$ 45,680$ & $\$ 22,840$ \\
\hline
\end{tabular}

Source:Takada and Breen, 2002, $n=1,089$ 


\section{PUBLIC-PRIVATE PARTNERSHIPS IN HEALTHCARE FINANCING}

on the estimate because of several limitations with the data. Since all purchasers are assumed to buy the mean priced policy, the analysis does not account for people's rational decision-making process facing their own budget constraints. Presumably, lower income purchasers would opt for less comprehensive policies which would cost less than the average policy. Also, the policy price quoted is for a more recent policy and represents current market conditions, so it is more expensive than a policy quoted in 1995 would have been. Another assumption was that each person in the income category could be represented by the midpoint income, which may be inaccurate. Unfortunately, a complete income distribution was not available.

Existing literature and independent analysis suggest that the 5 percent W'TP threshold is the most realistic for the Partnership market. The remainder of this analysis will focus on the potential market as predicted by the 5 percent value. One-way analysis of variance and means comparisons revealed significant differences on a variety of demographic characteristics among the members of each hypothetical market. At each ability to pay category, those able to afford the NYSPLTC are younger than those who cannot, with age increasing as a larger percentage of income is assumed to be available to cover premiums.

Estimates of the potential market demand for the NYSPLTC are a useful way to determine the impact of the policy. Self-reported income data collected on partnership purchasers in the 1995 survey demonstrates a weighted average ability to pay of 5.37 percent of income for policy purchase. Since this analysis relies on a variety of summary statistics and estimates and lacks specific data linking income level and policy cost, this value should be seen as representative of the upper bound of willingness to pay. Indeed, the 5 percent income threshold for ability to pay for a policy requires that the purchasers of the average NYSPLTC policy have a household income of at least $\$ 44,360$ per year, though many people with lower annual incomes participate as well.

Many of the characteristics that distinguish the potential Partnership market constituents from the overall state population also differentiate purchasers from nonpurchasers, suggesting that the purchasers form particularly elite groups within their classes. This is an issue of some concern because it implies that the Partnership program may not reach a representative population and excludes certain groups of citizens.

In order to determine who the Partnership could potentially reach, CPS data was analyzed to elicit demographic characteristics of households which can afford at least one policy. All information is self-assessed and reported by respondents. The variables are defined below.
Education Level:

Measured by a Likert Scale

(of increasing education levels)

$\begin{array}{ll}\text { 1-Some H.S. } & \text { 2-H.S. Grad 3-Some College } \\ \text { 4-College Grad } & \text { 5-Advanced Degree }\end{array}$

Age: measured in years

Health: Likert Scale

1-Excellent 2-Very Good 3-Good 4-Fair 5-Poor

Marital Status: Likert Scale

1-Married 2-Married, spouse absent 3-Separated

4-Widowed 5-Divorced 6-Never married

Metropolitan Statistical Area Type:

Geographic Identity

1-Central City 2-Within Statistical Metropolitan Area

3-Outside SMA . 4-Other

Income Category:

Self-reported dollar amount

$\begin{array}{ll}1-<\$ 15,000 & 2-\$ 15,000-\$ 30,000 \\ 3-\$ 30,000-\$ 50,000 & 4-\$ 50,000-\$ 75,000 \\ 5-\$ 75,000-\$ 100,000 & 6->\$ 100,000\end{array}$

White:

Dummy Variable- Ethnicity

$0=$ not White $\quad 1=$ White

Table 3: Differences between Potential LTCI Purchasers and Those Not Able to Afford LTCI

\begin{tabular}{|l|c|c|}
\hline Mean Values & Unable To Afford & Able To Afford \\
\hline Age & 68.7 & 54.9 \\
\hline Education Level & 2.72 & 3.81 \\
\hline Self-Perceived Health & 3.15 & 2.33 \\
\hline Marital Status & 3.09 & 1.91 \\
\hline White (dummy) & 0.79 & 0.84 \\
\hline MSA Type & 1.67 & 1.84 \\
\hline Median Income & $\$ 17,530$ & $\$ 72,290$ \\
\hline
\end{tabular}

Source: March, 2001 CPS, $n=2,929$

On average, New Yorkers who can afford the NYSPLTC are younger, more highly educated, healthier, more likely to be married and more likely to be white than those whose policies would be more than 5 percent of their annual household income. The potential purchaser group is less likely to live in an urban setting. Table 3 presents the differences between the potential purchasers and those who would not be able to afford the Partnership. All numbers reported are mean values except for household income, which reports a median value. This was a better measure of central tendency because it is less sensitive to the effects of outliers. All mean differences are statistically significant. 
These results underscore one of the major barriers to success facing the private LTCI market. Those who can afford the policies are generally younger. Younger people are more likely to have labor-force income streams and face lower premiums because of their lower probabilities of needing care. However, there is less incentive for them to buy coverage at this time because the need for care is not imminent. Insurers have trouble convincing younger people of the need for LTCI years before they can imagine requiring care.

\section{EVALUATING THE NEW YORK STATE PARTNERSHIP FOR LONG-TERM CARE}

Partnership policies generally cost as much or more than comparable non-Partnership policies. Therefore, the New Yorkers identified by the CPS data as able to afford the Partnership (56.7 percent at the 5 percent willingness to pay threshold) are also able to afford many other forms of LTCI. Analysis of the CPS and Partnership data raises as many questions as it answers when considering the benefits of a public policy geared toward these individuals. Given that purchasers tend to be younger and healthier than non-purchasers, the Partnership can claim success if they would not have purchased LTCI in its absence. If the state is just providing a form of backup asset protection insurance to people who merely substituted the Partnership for another private policy, then the Partnership may not be the right intervention to increase take-up in the private market.

Since Partnership policies compose a minority of the policies sold in the state ( 20 percent), it appears to be playing a limited role in encouraging private insurance purchases. If more than half of the households in the state can afford at least one LTCI policy, why are so few of them purchasing insurance? Results from the Partnership and CPS data suggest that the existing market failures in the private market- adverse selection, moral hazard, and purchasers with limited knowledge do more to discourage purchase than the Partnership is able to do to entice them. Overall, the people in the "able to pay" demographic have characteristics of "good risks" for insurers. The challenge to the state lies in finding the proper incentive to bring these people into the private market.

The average partnership purchaser enjoys a high level of physical health. It is desirable to have many people with these characteristics in the market because they have lower risks of needing care and lower the cost of insurance when pooled with the population at large. Unfortunately, it is unknown whether this is the result of self-selection or underwriting in the insurance market. While the former is a credit to the Partnership, the latter is more likely. When asked why their spouse did not also purchase a Partnership policy, 46.2 percent of purchasers in the 1995 survey with non-purchasing spouses indicated that their spouse did not pass the underwriting exam. The good health of purchasers is more likely to make them opt out of the private market if policies come to represent higher costs of people with significantly greater probabilities of needing care. The additional asset protection benefit, however, adds value that should keep healthier people in the market longer. This is an important way in which the Partnership may benefit the private market.

The average age of Partnership policyholders is sixtythree years - four years younger than the average purchaser nationally (Takada and Breen, 2002; HIAA, 2001). They are a much younger group than elderly longterm care users. The AHRQ reported that, as of 1994, the mean age of LTC users is 80.5 (AHRQ, 2000). Having a relatively young population is important because it minimizes incidence of adverse selection. Very few people can accurately predict their access to informal care or level of health 15 years in advance. However, purchasers do have to be reasonably confident that they will remain in New York State, as the Medicaid benefits do not transfer across state lines.

Ensuring that people who may not belong in the private insurance market are not being mistakenly led there in the interest of asset protection is also important given the limited knowledge that studies have shown purchasers to possess. Results of the Partnership's purchaser survey revealed that only 31 percent of purchasers were able to correctly estimate the cost of care in their area. Among those who underestimated or did not know the cost of care, 72 percent would face annual co-payments in excess of $\$ 10,000$ (in 1995 dollars) in the event of nursing home admittance. This suggests that the Partnership is not ameliorating the information failures that characterize the private insurance market. Intervention would be more desirable if it allowed those who were uninformed about long-term care to understand the true risks and make an informed purchase decision.

Another problem with LTCI involves decisionmaking under conditions of limited information. Purchasers can erroneously place themselves into one of two categories. The first type has enough assets to privately pay for long-term care insurance, but underestimates the cost of care in New York and does not buy enough insurance. Purchasers in the second category also underestimate the cost of care, but have lower income and asset levels than those in the former group. The latter purchasers would be better served by saving their money and going through Medicaid spend-down in the event that they do require long-term care. Those whose assets will be depleted by financing co-payments do not belong in the Partnership market because they will 


\section{PUBLIC-PRIVATE PARTNERSHIPS IN HEALTHCARE FINANCING}

not benefit from the asset protection clause. Purchase decisions by both of these groups merit attention because they suggest that the Partnership may be targeting the wrong population or failing to provide adequate information to purchasers. In either case, the state's intervention exacerbates existing market failures rather than improving upon them.

Since New York State has a limited budget for longterm care, it is important to determine the best allocation of public resources. There is a clear role for government intervention to correct the flawed decision-making behavior motivated by the imperfect information of purchasers. Anecdotal information from insurers suggests that people requested Partnership policies more when they were being advertised and numerous studies have showed that LTCI purchasers are more knowledgeable about long-term care than non-purchasers (Shahan, 2002; Morgante, 2001; Lifeplans, 2000). This indicates that information available to people motivates their purchase decisions and suggests that if resources were devoted to education rather than subsidies of insurance purchase, which tend to benefit those who would buy insurance anyway, the size of the misperception groups could be minimized. This could result in socially desirable outcomes where those who cannot really afford LTCI would divert their money to a utility-maximizing allocation and more affluent individuals would purchase the correct amount of insurance.

The Partnership is a publicly supported program, which introduces equity concerns with its impact. The public may not prefer to spend limited resources on care provision and asset protection for affluent, well-educated couples. However, if the Partnership entices people who would otherwise. spend down their assets and eventually rely on Medicaid to cover the cost of their care to shift risks to the private insurance market, the state will be able to increase spending for services benefiting poor elderly. The higher percentage of Partnership purchasers reporting that they would have used MEP absent the Partnership relative to those who did not buy suggests that the state may be encouraging personal responsibility among the right people. However, this is limited, self-reported data from a population that may not be representative of all Partnership purchasers. Without the chance to observe MEP behavior in a counterfactual situation where individuals do not have the opportunity to obtain additional Medicaid asset protection, these data are not strong enough to ascertain many strengths of the Partnership.

Conversations with the insurers suggest that many people still do rely on Medicaid Estate Planning and that choice of policy is partially dictated by a client's asset and income position. Horizontal equity suggests that people with similar endowments should be treated similarly by public policy. The Partnership violates this principle by refusing to treat people with equal amounts of total net worth as equals. A purchaser with the foresight to spend a lot of his savings on an annuity in order to ensure a. generous income stream through retirement will be penalized for his advance planning because he will be expected to contribute his income toward the cost of Medicaid long-term care once his private insurance benefits are exhausted. However, another policyholder who had converted his savings to housing equity by purchasing a lavish home for himself and his wife, paying monthly expenses with Social Security and a small pension would receive greater asset protection from the Partnership and contribute less to the overall cost of his care.

While proponents of the Partnership assert that it enhances the public good by shifting costs to the private insurance market that would otherwise be passed on to Medicaid, the extent of this claim has to be questioned (McCall, 1995). The data analyzed in this paper suggest that people able to afford the Partnership are significantly better off than those who cannot, and more likely to be able to draw upon informal support networks through their families. Therefore, unless these people engage in MEP, most of them should be able to afford much of the cost of their care and might be better off with a policy that provides a richer benefit stream or costs less, as several insurers had suggested.

All other things equal, vertical equity theory gives preference to the less wealthy, Society is assumed to be better off when people who cannot afford private services are able to consume a higher level of public services than those who can substitute through the private market. Encouraging Medicaid use as a form of asset protection increases the pool of competition for Medicaid nursing home beds, threatening to crowd out those with no other options. However, if the Partnership is only reaching the population with income and assets that would be depleted through Medicaid spend-down and merely prevents or delays the eventual event by making private insurance purchase more attractive, the state may not face any change in expenditures. In this case, the state benefits by enlarging the private market and actually reduces Medicaid spending on the more affluent.

While our government has generally encouraged policies that support homeownership and savings, a program such as the Partnership, which violates horizontal equity, distorts individuals' savings preferences and takes away their ability to maximize personal utility through a savings allocation that best suits their needs. By endorsing a distorted policy, the government assumes that the distorted preferences are more socially desirable than the outcome an individual would have selected independent of the government. However, there is little evidence to confirm that the present private insurance market or the Partnership program offers better outcomes for purchasers. The mean nursing home stay is only two and one half years, which 
means that, depending on their homecare needs, many purchasers will never qualify for Medicaid asset protection even if they are in the portion of the population which eventually requires some form of long-term care. Only 20 percent of nursing home patients nationally have stays in excess of 3 years (Cohen et al., 1992).

\section{FUTURE DIRECTIONS}

Both the quantitative data analyzed and the qualitative reports from insurers show that the New York State Partnership for Long-Term Care clearly targets a particular portion of the state population. It is not a viable option for those whose health or finances preclude them from passing insurance underwriting and paying annual premiums, despite the fact that this population is most likely to be using or spending down to Medicaid. The Partnership is not popular with widows or residents of urban areas, two groups frequently served by public support programs, especially in old age, A comprehensive response to problems of long-term care financing should incorporate these groups.

Medicaid is unprepared to finance the long-term care expenditures of the aging American population and as a means-tested support program should not be paying for the care of those who are able to contribute toward the cost of their own care. Thus far, the private insurance market has been unable to provide a viable alternative that reaches the majority of the population. Long-term care financing in the United States remains a situation where the market failures surrounding current alternatives indicates a role for government intervention. The NYSPLTC demonstrates that in some cases governments may only want to target particular segments of the population in order to improve overall market conditions. Future research should survey purchasers in order to determine whether the Partnership is an effective way to prevent MEP and bring younger, healthier people into the private insurance market. The asset protection clause increases the value of the policies to purchasers and may combat adverse selection by giving good risks more incentive to stay in the market.

Improving risk pooling in the private market enhances the public good because it leads to a greater availability of low-cost policies as the good risks lower the expected value of the overall loss. If government intervention can find more ways to bring these people into the private market, some of the presently observed problems in the public market can be mitigated.

Increased private insurance use can remove some of the long-term care financing burden from Medicaid by creating an affordable option for those with income and assets that would otherwise be spent down in order to pay for nursing home or home care costs.
Future long-term care financing initiatives should continue to try public-private partnerships in order to improve conditions and use of the private market. The government can encourage individual responsibility in care financing in order to ensure that there will be resources available to finance the care of everyone who needs it. If more people can be brought into the private insurance market, interventions from other countries can be used in conjunction with private insurance to improve conditions domestically. Research should also find ways for private insurance policies to compensate informal caregivers if they can provide effective care. Allowing patients more alternatives to institutional care enhances independence and prevents moral hazard (the tendency to over-consume care when one does not bear its full cost), because people are more likely to consume only the level of care that they need. Future research as well as collaboration between the public sector and the private insurance market can result in more socially desirable methods of long-term care in the future.

\section{NOTES}

' Policyholders can qualify for Medicaid after three years of nursing home care, six years of home care, or an equivalent combination of the two (NYSPLTC, 2001).

${ }^{2}$ This term refers to a non-institutionalized spouse who continues to rely on the couple's income.

${ }^{3}$ Gregory Serio (2001). Insurance Policies Covering Long Term Care Services in New York State. State of New York Insurance Department.

\section{REFERENCES}

Agency for Healthcare Research and Quality. The Characteristics of Long-Term Care Users, AHRQ Publication No. 00-0049, September 2000.

Bass, S., Morris, R. and Oka, M. (1996), Public Policy and the Old Age Revolution in Japan, Haworth Press, Inc.

Becktel, R. and Tucker, N. G. (1998). Across the states 1998: Profiles of long-term care service systems. Washington: AARP Public Policy Institute.

Biegel, D. and Blum, A. (1990), Ageing and Caregiving, Sage Publications.

Burrel, B. (2001), Medicaid long-term care expenditures in fiscal year 2000. The Gerontologist, 40, 687-691.

Caldwell, B, (1994). Partnerships broaden long-term care awareness in four states. Employee Benefit Plan Review, 49, 36+. 


\section{PUBLIC-PRIVATE PARTNERSHIPS IN HEALTHCARE FINANCING}

Charsky, D. (2001). Buyers and Non-Buyers of Long-Term Care Insurance: A Decade of Experience. Presentation to the Health Insurance Association of America 12 October 2001.

Cohen, M.A., Kumar, N., McGuire, T., and Wallack, S.S. (1992). Financing long-term care: A practical mix of public and private. Journal of Health Politics, Policy and Law, 17, 403-438.

Cohen, M.A., Kumar, N., McGuire, T., and Wallack, S.S. (1993). New perspectives on the affordability of long-term care insurance and potential market size. The Gerontologist, 33, 105-113.

Cohen, M.A., Kumar, N., and Wallack, S.S. (1994). Long-term care insurance and Medicaid. Health Affairs, 13, 127-139.

Cohen, M.A., Miller, J., Weinrobe, M. (2001). Patterns of Informal and Formal Caregiving among elders with private long-term care insurance. The Gerontologist, 41, 180-187.

Cohen, Marc and Weinrobe, M. Tax Deductibility of LongTerm Care Insurance Premiums: Implications for Market Growth and Public LTC Expenditures. March 2000. Downloaded from http://www.hiaa.org.

Coleman, B. (2000), Helping the Helpers. State-Supported Services for Family Caregivers, AARP Public Policy Institute.

Connecticut Office of Policy and Management. (1996). The Connecticut Partnership for Long-Term Care: Evaluation Study for 1995.

Connecticut Office of Policy and Management. (2001). The Connecticut Partnership for Long-Term Care: Evaluation Study through June 2000.

Curry, Leslie et al. "Medicaid Estate Planning: Perceptions of Morality and necessity" The Gerontologist, February 2001.

Davidson, S. and Marmor, T. (1980), The Cost of Living Longer, Lexington Books.

Feder, J., Komisar, H. and Niefeld, N. "Long-term care in the United States: An overview" Health Affairs May-June 2000.

Grabowski, D. (2001), Does an increase in the Medicaid reimbursement rate improve nursing home quality? The Journals of Gerontology Series B, $56 B, \mathrm{~S} 84$.

Gruber, J. (2000). Medicaid. National Bureau of Economic Research Working Paper 782.

Harrington, S. and Niehaus, G. (1999). Risk Management and Insurance, Irwin McGraw-Hill.

Hosmer, D., Taber, S. and Lemeshow, S. (1991). The importance of assessing the fit of logistic regression models: A case study. The American Journal of Public Health, 81, 1630-1635.
Ikegami, N. (1998), "The Rationales for Establishing Independent Long-Term Care,' in Aging and Health: Proceeds of the World Health Organisation Kobe Symposium (1998).

Kassner, E. (1999), Long-Term Care Insurance, AARP Public Policy Institute.

Kassner, E. (2000), In Brief: Medicaid Financial Eligibility Rules Can Affect Access to Home Care, AARP Public Policy Institute.

Kirkwood, A. and Astle, J. (1997), Long-Term Care: A Framework for Reform, Institute of Community Care.

Koinuma, N. (1998), 'Long-Term Nursing Care Insurance in Preparation for the Super-Aged Society,' in Aging and Health: Proceeds of the World Health Organisation Kobe Symposium (1998).

Levin, N. (1999). A report by the superintendent of insurance to Governor Pataki and the legislature on the implementation of legislation permitting approval of certain long-term care health insurance plans.

Mathieson, K, Kronenfeld, J. and Keith, V. (2002). Maintaining functional independence in elderly adults: the roles of health status and financial resources in predicting modifications and use of mobility equipment. The Gerontologist, $42,24-31$.

McCall, N., Driver, S., Bauer, E., and Knickman, J. (1997). The partnership for long-term care: who are the partnership policy purchasers? Medical Care Research and Review, 54.

McCall, N., Mangle, S., Bauer, E. and Knickman, J. (1998). Factors important in the purchase of partnership long-term care insurance. Health Services Research, 29 187-203.

McCormick, J, and Chulis, G. (2000). Characteristics of Medicare persons in long-term care facilities. Health Care Financing Review, 22, 175-180.

Meiners, M. (1998). Enhancing the market for private longterm care insurance, Business and Health, 5, 19-22.

Mellor, J. (2000). Private long-term care insurance and the asset-protection motive. The Gerontologist, 40, 596-604.

Moon, M. (1993), Medicare Now and In the Future, Urban Institute Press.

New York State Partnership for Long-term Care. (2002). About the NYSPLTC, Medicaid and the NYSPLTC, Nursing Home Rates and Policy Sales. Downloaded from http://www.nyspltc.org.

New York State Partnership for Long-term Care. (1996), Unpublished data collected from surveys of purchasers, nonpurchasers and laspers. 
Pauly, M.V. (1990). The rational nonpurchase of long-term care insurance. Journal of Political Economy, 98, 153-168.

Pampel, F. (2000). Logistic Regression. Sage Series: Quantitative Applications in the Social Sciences 18-38.

Penning, M. (2002). Hydra Revisited: substituting formal for self- and informal in-home care among older adults with disabilities. The Gerontologist, 42, 4-16.

Prescott, N. (1998), Choices in Financing Health Care and Old-Age Security, The World Bank.

Private long-term care insurance: a new sub-specialty of elder law. New York State Bar Journal.

Quadango, J. (2002). Aging and the life course, McGraw-Hill.

Raetzman, S and Joseph, S. (1999). Long-term care in New York: Innovation in care for elderly and disabled people. The Commonwealth Fund Issue Brief.

Robert Wood Johnson Foundation. (2001). Program to promote long-term care insurance for the elderly. Downloaded from http://www.rwjf.org.

Royal Commission on Long-Term Care. (1999), With Respect to Old Age: Long-Term Care - Rights and Responsibilities.

Royal Commission on Long-Term Care. (1999), With Respect to Old Age: Long-Term Care-Rights and Responsibilities, Research Volume 1.

Rushing, W. (1986). Social Functions and Economic Aspects of Health Insurance, Kluwer.

Seki, E. (1998), "The Profiles and Challenges of Ageing Population- the Case of Japan,' in Ageing and Health: Proceeds of the World Health Organisation Kobe Symposium (1998).

Seio, Gregory, 1997. The Implementation Of Legislation Permitting Approval of Certain Long Term Care Health Insurance Plans. Presented to the NY State legislature, 1 February 1997.

Sloan, F.A. and Norton, E.C. (1997), Adverse selection, bequests, crowding out, and private demand for insurance: Evidence from the long-term care insurance market. Journal of Risk and Uncertainty, 15, 201-219.

Sorrel, T. (1998), Health Care, Ethics, and Insurance, Routledge. U.S. Census. (2001). 2000 Summary Data File 1. Downloaded from http://www.census.gov.

Takada, A. and Breen, P. (2002). The New York State Partnership for Long-Term Care: Quarterly Report, July 1, 2001 - September 30, 2001. Downloaded from www.nyspltc.org.
Voigtlander, H. (1980), 'Financing of Eldercare and Support in the Future,' in Ageing and Health: Proceeds of the World Health Organisation Kobe Symposium (1998).

Walker, L., Bradley, E. and Wetle, T. (1998) Public and private responsibilities in long-term care: Finding the balance, Johns Hopkins University Press.

Weiner, J., Hanley, R., and Illston, I. (1992). How much public? How much private? Journal of Health Politics, Policy and Law, 17, 425-433.

Weiner, J. and Stevenson, D. (1998). State policy on long-term care for the elderly. Health Affairs, 17, 81-100.

Weiner, J., Tilly, J. and Goldenson, S. (2000). Federal and State Initiatives to jump start the private long-term care insurance market. The Elder Law Journal, 8, 57-102.

World Bank. (1994). Averting the old age crisis. Oxford University Press.

Yamada, T. (1998), 'Preferences of the Japanese Elderly and Policy Implications for Public Health Services and Family Support,' in Ageing and Health: Proceeds of the World Health Organisation Kobe Symposium (1998). 